\title{
SMARCB1 Negative
}

National Cancer Institute

\section{Source}

National Cancer Institute. SMARCB1 Negative. NCI Thesaurus. Code C150645.

An indication that expression of SMARCB1 has not been detected in a sample. 